\title{
Vulnerability to climate change: people, place and exposure to hazard
}

\author{
C. W. Hutton ${ }^{1}$, S. Kienberger ${ }^{2}$, F. Amoako Johnson ${ }^{3}$, A. Allan ${ }^{4}$, V. Giannini ${ }^{5}$, and R. Allen ${ }^{6}$ \\ ${ }^{1}$ GeoData Institute, University of Southampton, UK \\ ${ }^{2}$ Centre for Geoinformatics, University of Salzburg, Salzburg, Austria \\ ${ }^{3}$ School of Social Sciences, University of Southampton, UK \\ ${ }^{4}$ Centre for Water Law, Policy and Science, Dundee, UK \\ ${ }^{5}$ Fondazione Eni Enrico Mattei, Venice, Italy \\ ${ }^{6}$ ICIMOD, Katmadu, Nepal
}

\begin{abstract}
The Human Dimension of the Twinning European and South Asian River Basins to Enhance Capacity and Implement Adaptive Management Approaches Project (EC-Project BRAHMATWINN) is aimed at developing socio-economic tools and context for the effective inclusion of the "Human Dimension" or socio-economic vulnerability into the overall assessment of climate risk in the twinned basins of the Upper Brahmaputra River Basin (UBRB), and the Upper Danube River Basin (UDRB) . This work is conducted in the light of stakeholder/actor analysis and the prevailing legal framework.

In order to effectively achieve this end, four key research and associated activities were defined:
\end{abstract}

1. Identifying stakeholders and actors including: implement an approach to ensure a broad spread of appropriate stakeholder input to the assessment of vulnerability undertaken in Asia and Europe within the research activities of the project.

2. Contextualising legal framework: to provide an assessment of the governance framework relating to socio-environmental policy development within the study site administrative areas leading to the specific identification of related policy and legal recommendations.

3. Spatial analysis and mapping of vulnerability: providing a spatial assessment of the variation of vulnerability to pre-determined environmental stressors across the study areas with an additional specific focus on gender.

4. Inclusion of findings with the broader context of the BRAHMATWINN risk of climate change study through scenarios of hazard and vulnerability (subsequent chapters).

This study utilises stakeholder inputs to effectively identify and map relative weightings of vulnerability domains, such as health and education in the context of pre-specified hazards such as flood. The process is underpinned by an adaptation of the IPCC (2001) which characterizes Risk as having the components of Hazard (physiographic component) and Vulnerability (socio-economic component). 

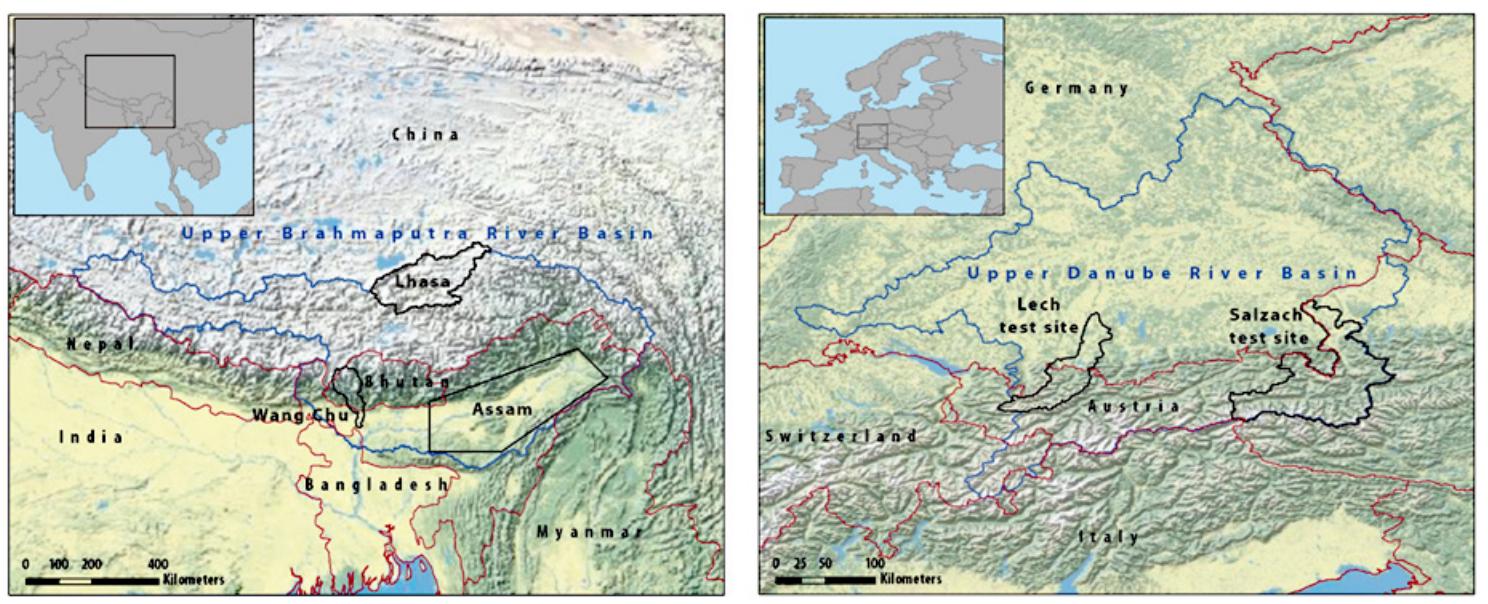

Figure 1. Outline location maps for key study sites within the BRAHMATWINN project.

\section{Introduction}

Climate change and its resulting effects on the environment, affects the socio-economic wellbeing of individuals, households, communities and nations. The impacts are mainly adverse, with some being irreversible, while others may be beneficial (O'Neil et al., 2001). The effects vary greatly and are felt more among the poorest of the poor and vulnerable communities due to limited resources and infrastructure available to these groups. The study presented in this chapter covers a number of case studies in the Upper Brahmaputra River Basin and the Upper Danube River Basin. These being the Assam State Brahmaputra river section (NE India), the Wang Chu River Basin in Bhutan and the Lhasa River basin in the Autonomous Region of Tibet along with the Salzach and Lech River basins of the Upper Danube in Europe. These case studies are selected on the basis that they represent basins/sub-basins under potential environmental threat due to climate change.

Vulnerability to climate change maps predominantly derived from census and land cover mapping provide a context for assessing vulnerability and the potential for adaptive capacity with regards to climate hazards in the selected twinning river basins (Fig. 1). Critical to this process has been the development of a joint (twinned) approach to the concept of vulnerability in the framework of risk and hazard as well as identifying the adaptive capacity and sensitivity components of vulnerability based upon the framework generated by the IPCC (2001) (Fig. 3). The project also includes an emphasis on gender perspective in order to developing a better understanding of the socio-economic impacts caused by climate stress on individuals, their households and communities in terms of their livelihoods, health and sanitation situations.

This chapter elucidates the methodological development of a stakeholder based flood vulnerability mapping within the study areas of the BRAHMATWINN project. As stated,

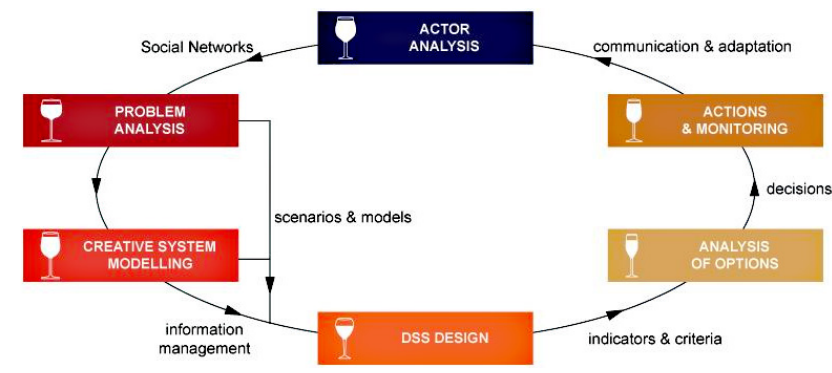

Figure 2. The NetSyMoD approach. The first 3 stages are utilsed in this approach.

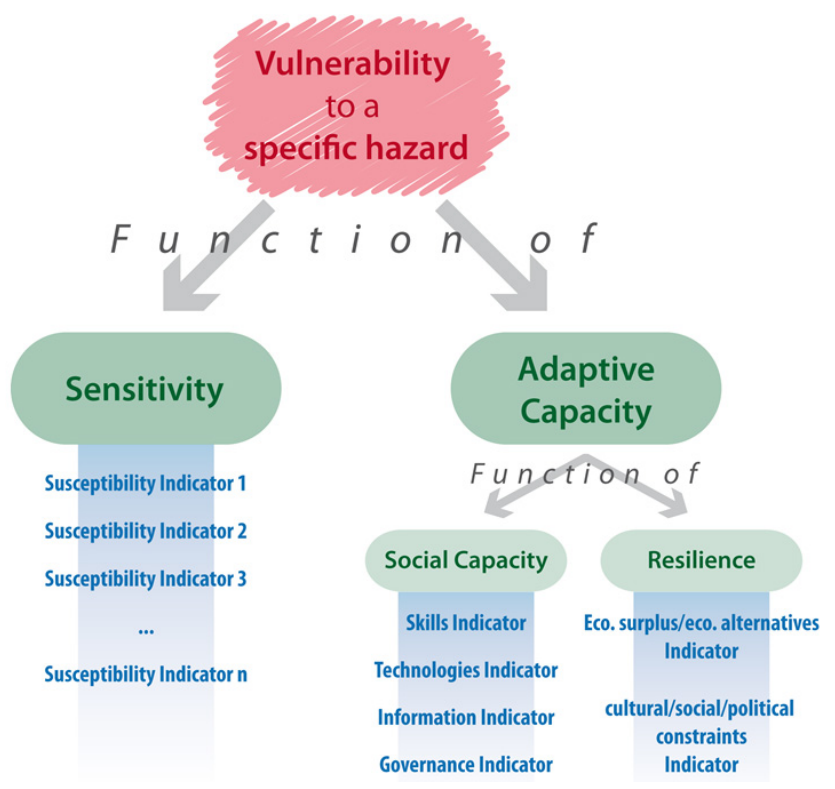

Figure 3. Conceptual model of vulnerability. 
the key aim is to provide a spatial context for the assessment of socio-economic and asset based vulnerability at risk from specific hazards associated with climate change. As such a process of identifying local and regional stakeholders to underpin this process is critical to the overall sustainability of the project outputs as well as providing the context for the identification of relevant indicators and their weighting for the development of vulnerability mapping approaches.

For this purpose, the project applies the implementation of a participatory planning methodology throughout the different phases of the work. The selected participatory approach utilised within the process of eliciting stakeholder opinion is called Creative System Modelling (CSM) (Giupponi et al., 2008) which helps to identify participants and organises the structured debates in workshops, and is combined with a partial "Delphi" ranking round which allows the gathering of specific weightings for suggested domains of vulnerability. The process is supported by analysis relating to assessments of government efficacy and relevant legal structures and frameworks which providing a government context for understanding the potential impact of climate change and water resource management at a number of administrative levels in both the Asian and EU twinning basins.

Finally, all products outputs and methodological tools including data has been populated into the River Basin Information System (RBIS) which provides a common repository and organisation structure for the overall project outputs thereby enhancing the RBIS towards a Decision Information Support Tool (DIST) (BRAHMATWINN Chapter 10).

\section{Role within the international BRAHMATWINN project}

The role of "Human Dimension" (HD) within the BRAHMATWINN project is focused upon stakeholder, socioeconomic and governance framework contribution to the effective development of Integrated Water Resources Management (IWRM) strategies. In principle the BRAHMATWINN project can be thought of as developing Risk scenarios for the future climate impacts in the study basins, where Risk is considered to have the elements of Hazard, which is covered in the physiographic studies and analysis of the climate change models, and Vulnerability (socio-economic) which are essentially the stakeholder, governance and vulnerability mapping components. As such there is a social and a physical component and the project addresses both of these to develop integrated tools to be utilised by decision makers for the purposes of policy planning, development and implementation. BRAHMATWINN Chapters 3 (physical) and 4 (social) represent this division of work which are then integrated within the broader context of the project overall in later chapters.

\section{Methodology}

This chapter identifies a series of quantitative and qualitative methodological approaches which when combined allow for the production of vulnerability maps in both the European and Asian context, both of which are incorporative of stakeholder opinion (to a first order) and contextualised within the legal and policy framework independently. For the sake of clarity the below methodological approach differentiates these methodologies into two key approaches (i) stakeholder processes (ii) mapping methods. The key conceptual framework utilized is demonstrated in Fig. 3 which depicts the components of vulnerability based upon the adapted principles of the IPCC (2001).

\subsection{Stakeholder analysis methodologies}

\subsubsection{Identifying stakeholders}

The project requirement was to elicit and capture the stakeholder perspective in order to develop vulnerability maps that are reflective of local expertise and understanding. In order to achieve this, a process of Actors Analysis was undertaken which is an iterative identification of actors (stakeholders, experts etc.) to be involved in the process. In addition their reciprocal relationships within the actor networks were assessed using Social Network Analysis (SNA) techniques. This process formed the formative elements of a larger project wide process of social analysis termed NetSyMoD. In sequence and in parallel, in depth problem analysis is conducted in order to acquire the basic information about the case, the possible options, etc. (Problem Analysis). Once the community of interested parties has been identified and the problem in question analysed, Creative System Modelling (CSM) techniques (e.g. cognitive mapping) are applied to produce a shared model of the system underlying the problem (Creative System Modelling). The model is a formal, albeit simplified, description of the system and its causal links, to which the problem pertains and that can be commonly understood and recognised by the actors involved. It thus brings together simulation models, perceptions and beliefs of stakeholders and policy makers, as well as decision analysis techniques and underlying models. This process was utilised by the research activities expressed in this chapter as well as forming the foundation for further more detailed analysis of social network conducted and reported in Chapters 6 and 8 respectively.

\subsubsection{Government and legal framework}

The methodological approach adopted relies heavily on existing projects designed to measure governance in general, such as UNDP, World Bank, Access Initiative, and Transparency International. A review of these projects has lead to an understanding of the need to separate governance into 


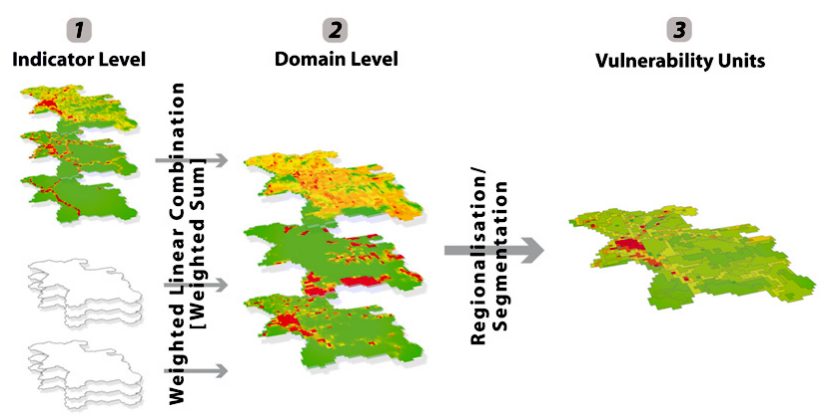

Figure 4. Workflow developed to model spatial vulnerability units in the Salzach River catchment (Kienberger et al., 2009).

questions related to commitments and processes. Commitments referring to what states have adopted on paper, and processes relating to the mechanisms that are in place to ensure that the commitments are implemented within the national, regional and local context. The study has also illustrates that the best approach to gathering indicator based information is to develop a set of questions designed and structured in a way that provides key information concerning the four elements of governance, i.e, accountability, transparency, predictability and participation

\subsubsection{Ranking of domains - the Delphi technique}

At the stakeholder workshops, a Delphi technique was used to investigate the relative importance of each domain identified. A domain represents a key area potentially impacting vulnerability such as health or education or different types of assets. Each participant was asked to score the domains to sum up to a total score of 40 , with the most important domain receiving the highest score and the least important receiving the lowest score. In Assam, the exercise was undertaken separately for each type of hazard (flood, drought and bank erosion) and for climate change and climate disasters for Bhutan. In the European case studies the hazard flood has been investigated solely. The sensitivity and adaptive capacity domains were ranked together to reveal their relative importance. The scores were then averaged over the number of participants and ranked in order of importance. The rankings of the domains are shown in Fig. 5. The exercise provided a preliminary classification of the different domains of sensitivity and adaptive capacity and their relative importance with regards to the different types of climate hazards. Figure 5 shows that in Assam, general access to clean water and sanitation facilities, disruption to livelihood sources, lack of access to health care and the lack of economic alternatives were ranked to contribute highly to vulnerability to climate hazards. Gender, immigration, human capital and social networks were ranked low in the final outcomes.

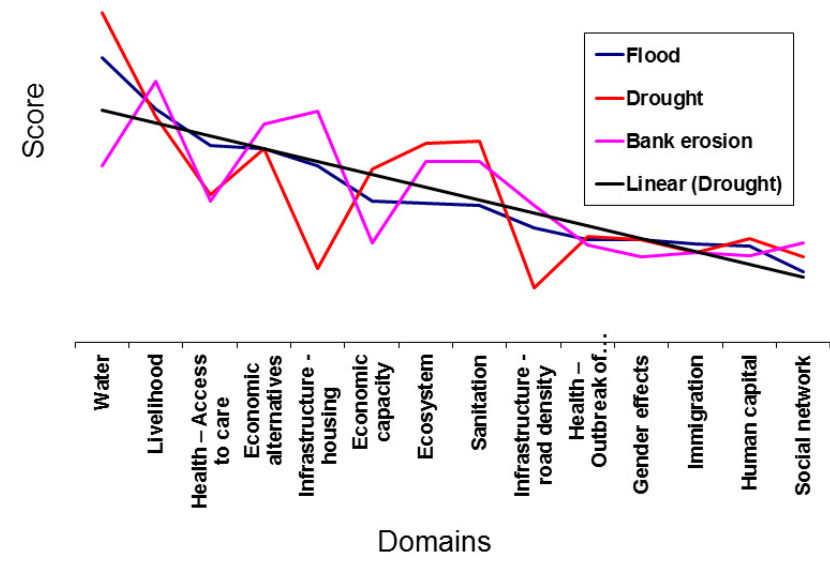

Figure 5. Domain weighting with hazard.

\subsection{Vulnerability mapping method}

Within a twinning framework of the BRAHMATWINN project an approach has been developed to effectively model and map vulnerability to floods in the UBRB (India, Bhutan and Tibet) and the UDRB (Salzach and Lech catchments). The full statistical method is outlined in Sharma et al. (2010). The intention of the research was to assess the socioeconomic component of risk through a joint vulnerability approach. The approach reflects the wider objective and conceptualizations of the International Panel for Climate Change (IPCC) framework (2001). Within this framework vulnerability is defined as a function of adaptive capacity and sensitivity. As sensitivity and adaptive capacity are multidimensional constructs a wide range of possible input parameters or domains are potentially of relevance and there is a need to be pragmatic about the datasets available and the subsequent selection of indicators. To enhance the range for parameter selection, the research methodology utilises census and household survey as well as land use/land cover data to derive and assess vulnerability. For both test site areas, appropriate indicators have been chosen from these sources and represented in sub-domains and domains based upon literature and in-field interviews and substantial workshops with local experts.

\subsubsection{European case study methodology: Upper Danube River Basin (UDRB) - Salzach catchment and Lech catchment}

In the Salzach and Lech catchment it was aimed to model homogenous regions which share a a common property of vulnerability. The methodology developed and the results for the Salzach catchment are documented in Kienberger et al. (2009). The derivation of homogenous spatial units links to concept of Geons (Lang et al., 2008) which are defined as generic spatial objects that are homogenous in terms of a varying spatial phenomena under the influence of, and partly 
controlled by, policy actions. The Geon concept acts as a framework for the regionalization of continuous spatial information according to defined parameters of homogeneity

Data applied, to populate the specific indicators and domains, originates from publicly available GIS data sources and census data. The data is not only provided on the basis of different administration units, but additionally on a standardised grid (in this case $1000 \mathrm{~m}$ ). This is a unique approach and allows visualising data not only on the arbitrary administration units but shows the characteristics in a spatial distribution. Another advantage is that in subsequent analysis steps the Modifiable Areal Unit Problem (MAUP, Unwin, 1996) is minimized. Next to the census data, data on infrastructure, the availability of early warning systems, distance to first responders and heath facilities and land use/land cover information defining different asset classes have been integrated.

In principle the methodology (Fig. 4) follows in a first step the approach of Multi Criteria Analysis (MCA), Multi Criteria Evaluation or Analytical Hierarchy Process (AHP) where a discussion on that topic and current best practices approaches is available in Carver (1991) and Malczewski (2000). This method is applied to allow the comparability of the different data layers and aggregate the data to the different sub-domain levels through weighted sum algorithms. To finally model vulnerability units the regionalisation algorithm after (Baatz and Schäpe, 2000).has been applied.

The integration of expert knowledge was maintained through the identification of indicators and sub-domains, and the weighting of the different domains which was achieved through an online Delphi exercise with stakeholders from the Salzach and Lech basins This weights have then be used within the weighted sum aggregation and within the regionalisation algorithm which also considers the integration of scores/weights.

In a final step the data has been visualised next to papers maps, also as virtual globe environments, which allow the exploration and visualisation of this hierarchically structured data.

\subsubsection{Asian case study: Upper Brahmaputra River Basin (UBRB) - Assam, India (main case study), Wang Chu River Basin, Bhutan and Tibet (ART)}

The data for the analysis comes from the 2001 Indian Population and Housing Census and 2001 LANDSAT data for the UBRB. For Bhutan, the 2005 Population and Housing Census and remote sensing data were used, and the analysis was conducted at the Gewog administrative level. Although the study area (the Wang Chu) covers 35 Gewogs, for the purposes comparison the analysis was conducted for all 201 Gewogs of Bhutan. The Tibetan study was limited to LANDSAT data only as there was substantial difficulty accessing any socio-economic data of relevance.

The LANDSAT data include road density, agricultural land use, distance to main settlements and health cen- tres. The road density and agricultural land use data were extracted using a three kilometre buffer around each village/town point. Agricultural land use is expressed as the proportion of land use on the basis of commercial and noncommercial agricultural land. The distance measures (distance to main settlements and health facilities) are Euclidean distances. The data covers 14775 towns/villages of the in UDRB.

The different domains of sensitivity and adaptive capacity were identified through literature review, field observations, and discussions with local residents, stakeholders and experts working on both the hydrological and socio-economic aspects of environmental hazards in the region. This process was used to develop an inventory of domains and indicators that can be used to profile vulnerability. Indicator selection for vulnerability profiling has been debated extensively in the literature (Jones and Andrey, 2007). The debate has focused on the justification for inclusion and exclusion of indicators. Studies such as Cutter et al. (2000); Wu et al. (2002); Odeh (2002); Brooks et al. (2005); Chakraborty et al. (2005); Jones and Andrey (2007) have used different indicators to quantify vulnerability. Some studies have used Principal Component Analysis (PCA) and correlation methods to select indicators for vulnerability profiling (Jones and Andrey, 2007; Brooks et al., 2005). The advantages and disadvantages of these methods have been discussed in the literature (Jones and Andrey, 2007). The disadvantages mentioned in the literature have focused on the reliability of the indicators to measure vulnerability in a given location.

To avoid this potential bias, a participatory process involving local residents, stakeholders and experts were employed (CSM). The criteria for selection of indicators was based on what local residents, stakeholders and experts thought appropriate, relevant and robust for quantifying a specific domain. It is worthwhile mentioning that not all indicators identified by local residents, stakeholders and experts were included in the analysis due to data limitations. The indicators selected for the analysis although may not be exhaustive for assessing environmental hazard induced vulnerability; they have been selected to ensure that it is comprehensive and relevant for the practical assessment of vulnerability to environmental hazards in the given location. The indicators although may not be replicated exactly for other regions they could be modified to suit.

\section{Results}

The results of the Assam basin vulnerability mapping in the Brahmaputra basin (Fig. 6) are presented as a map of community points of output vulnerability classes for flood hazard. Each point represents the centroid of a community identified on the Indian census (2001) with a population represented through the size of the circle. It was not possible to access the data regarding the actual spatial extent of the 


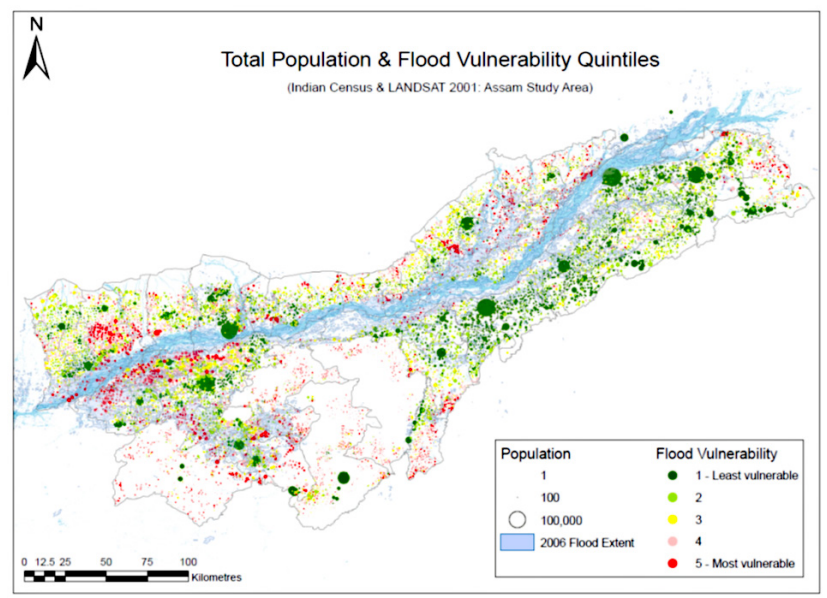

Figure 6. Vulnerability to flood based upon the geo-referenced Indian census data (2001) and a weighted indicator approach. Flood extent of a large recent flood is used as a proxy for hazard. Mapped by settlement.

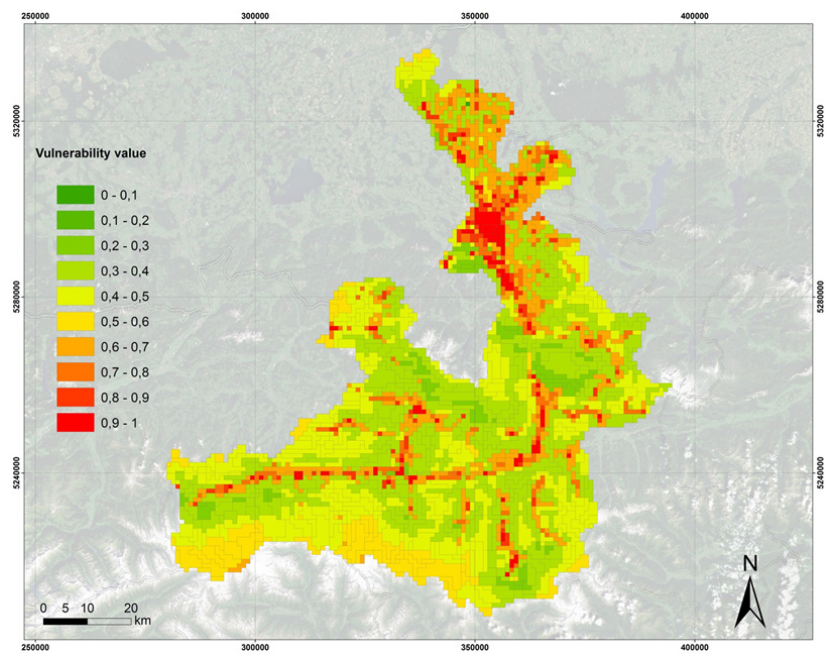

Figure 7. Bhutan case study: Climate change impacts on agricultural calendar/socioeconomic development (shift in precipitation/weather patterns) - by Gewog.

communities which would have added another valuable element. Figure 5 shows that the same process was carried out for drought and bank erosion as well with substantial weighting variations elicited form stakeholders. For Bhutan the result are constructed in a comparable fashion however the unit of analysis is the larger administrative unit out of necessity (Fig. 7). As stated earlier the output for Tibet is based only on satellite imagery and represented on a $1 \times 1 \mathrm{~km}$ grid (Fig. 8).

In the Salzach and Lech basins (Figs. 9 and 10), due to the availability of grid-based census data, the method to delineate and identify homogenous units/areas of vulnerability has been achieved independent from administrative units (Kienberger et al., 2009). Similar to the approach applied in Assam, the vulnerability is measured on a relative scale. The

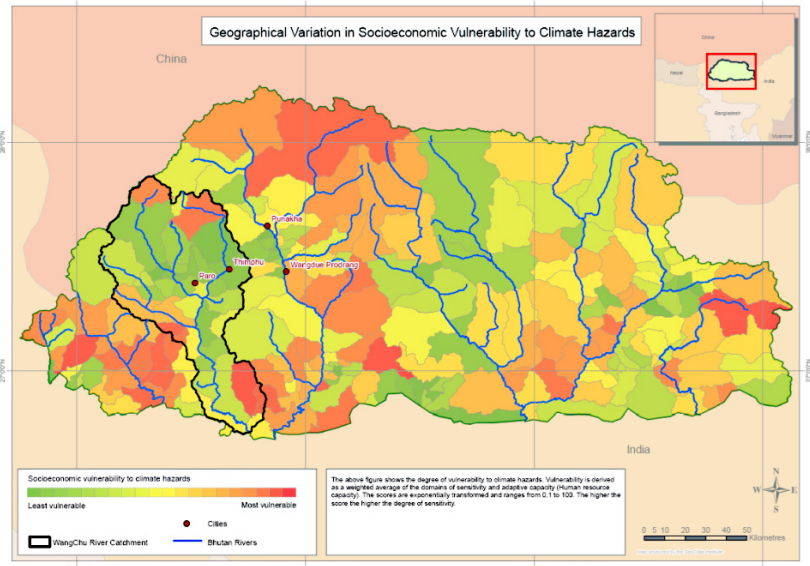

Figure 8. Tibet case study: Climate change hazard with associated impacts on agricultural calendar/socioeconomic development. Based upon LANDSAT only.

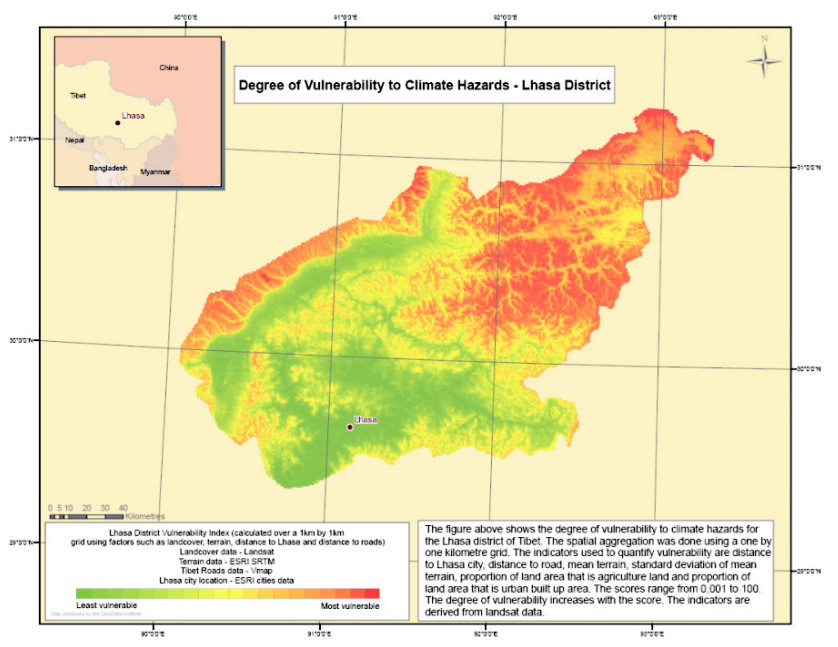

Figure 9. Salzach River case study. Socio-economic Vulnerability unit.

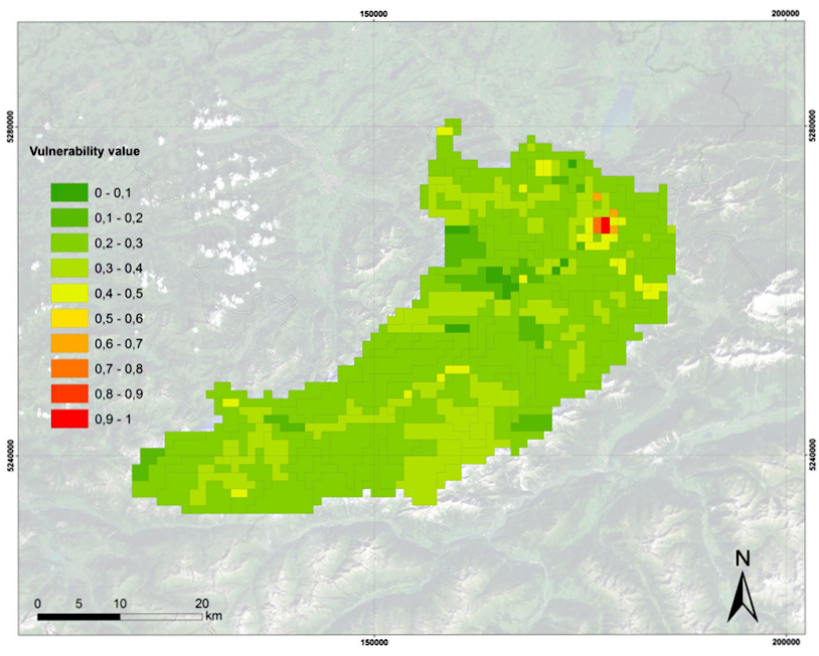

Figure 10. Lech River case study. Socio-economic Vulnerability units. 

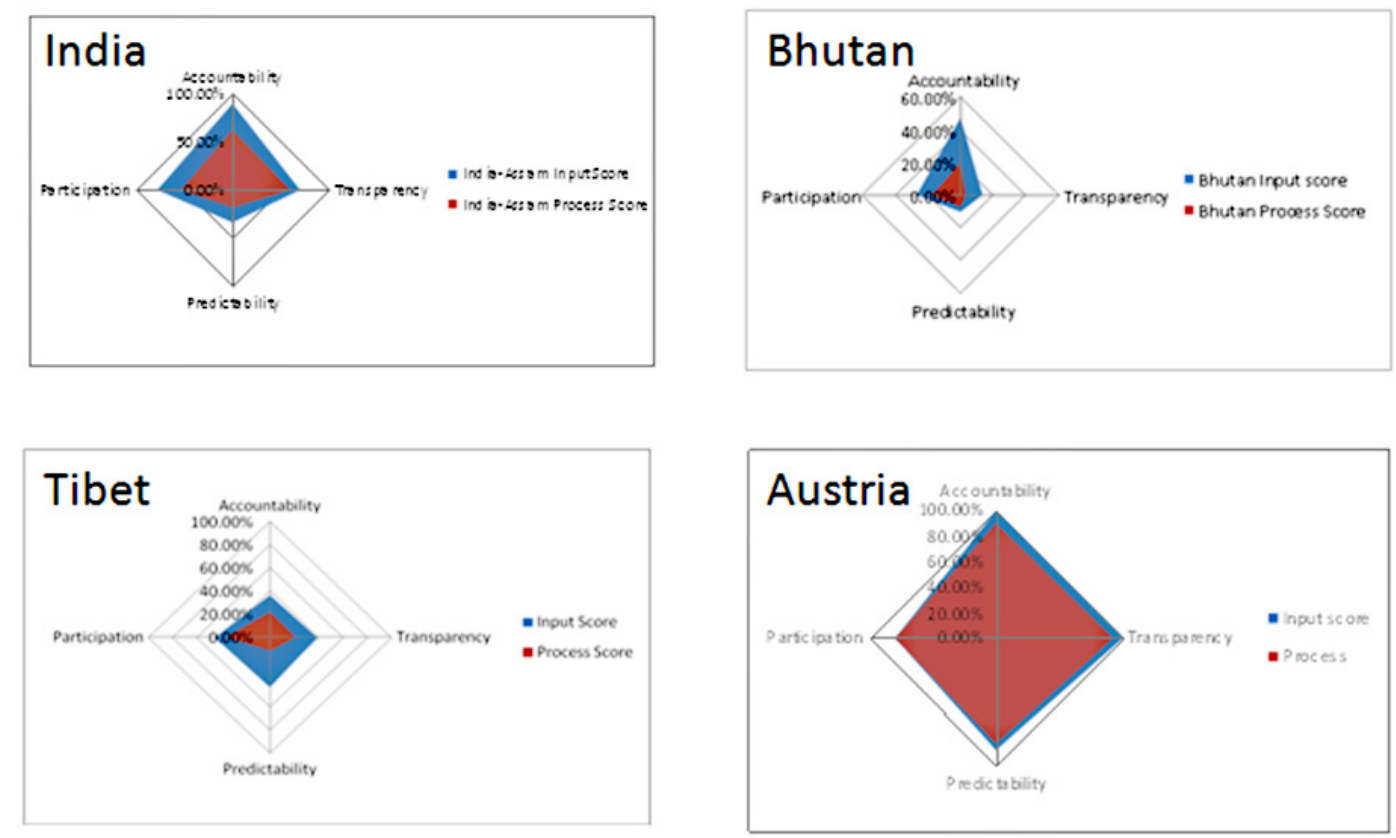

Figure 11. Attributes of the water resources government framework for the study area authorities. Input refers to the current legal framework in place and output refers to implementation.

modelling result show a high vulnerability in areas related to assets and infrastructures. Additionally, it can be observed that domains/indicator have been highly weighted through the stakeholder have a significant "imprint" on the results such as factors within the susceptibility domains "housing", "infrastructure" and "assets" and the social capacity domain "early warning" which received the highest ranks.

Both sets of maps rely upon a common conceptual framework to develop the vulnerability maps, however there is no intention to absolutely standardise approaches, indeed it is deemed of specific value to allow the selection and fulfilment of domains to be suited to the regional requirements. As such the twining referred to in the BRAHMATWINN project is limited to a conceptual level.

Figure 11 is a visualisation of the governance framework which has precedence over the study areas. The spider diagrams allow a comparison of the key attributes of good governance and provide a focus for potential enhancement of the current legal framework from the perspective of both the development of law and its application. The ultimate aim of answering the "indicator" questions is to provide a structured analysis of the extent to which existing governance arrangements within a country facilitates IWRM in the context of climate change. In separating commitments and process questions, the analysis can also assess the extent to which commitments have been realised.

\section{Contribution to sustainable IWRM}

Vulnerability and associated risk mapping offers decision makers a quantitative and well framed pathway into the incorporation of socio-economics to IWRM planning. To this end the contributions of Chapter 4 are seen as inputs to two key further elements of the project. The follow-up study to the work presented in Chapter 4 is presented in Chapter 8 which deals with the specific development of "what if scenarios" and Chapter 10 which identified the role of these outputs in the broad IWRM context. The main aim of this further work is to investigate the potential for vulnerability to increase or decrease depending on governments' policy directions and social values under the four scenarios related to the SRES outcomes. In Chapter 10 this outcome is considered in the context of IWRM more specifically. To do this all the individual variables that are highly correlated with the overall vulnerability score are identified and the outcomes linked to the economic and demographic development of the region as forecast for all India under the SRES scenarios. In broad conclusion the impact of GDP and population growth is seen to be highest in areas where levels of vulnerability are already high.

\section{Conclusions and recommendations}

A valuable outcome of the twinning approach has been the delineation of two clear paradigms in the thinking of the production and utilization of vulnerability maps. In the European context of the UDRB vulnerability is strongly 
characterised through assets, whereas in the Assam region of the Asian UBRB a strong focus lies on the defining characteristics of poverty at the community level. As such, in the Asian context, it is possible that a map of asset vulnerability is the inverse of a vulnerability map based upon community vulnerability. Both sit within a distinct governance and legal context which clearly delineates the complex associations between vulnerability and the strengths and weaknesses of policy and its implementation.

As indicated earlier it was not intended within the specific research context to allow a direct comparison of the vulnerabilities between the Salzach River catchment and Assam. Building on a joint conceptual framework, for each case study area specific indicators have been selected. This depends on one hand pragmatically on the availability of datasets but even more on the characteristics of vulnerability in the specific areas and the input from different stakeholder workshops, which targeted on the identification of characteristic vulnerability indicators. One element of that input that came under discussion was the role of the experts (project partners) who are not necessarily regional experts. It was felt it was important to minimise input from external sources and simply to facilitate opinion of stakeholders. To this end such domains as gender, which has a strong EU imperative were not given substantial weighting due to local expert opinion settling against them and despite partner expertise prioritising such a domain. As such the maps represent the perceptions of vulnerability of that group of individuals that were gathered together in the stakeholder meeting. This approach was a pilot and of course with more resourcing and time there would need to be a far more exhaustive exploration of the stakeholder opinion. An example of this was the strong bias towards engineers in the Assam workshop as there is a tendency for decision makers in this region to have an engineering focus. The workshop was representative of decision making in Assam but perhaps not representative of governance more broadly.

To implement successfully measures in regard to disaster risk reduction and climate change adaptation actors from national governments, provincial administrations and local authorities need to plan interventions based on location. It has been widely agreed that regional development and planning is a highly multidisciplinary such as the identification of land use changes. This integrates experts and stakeholders from different disciplines or ministries and should be best achieved through the involvement of the vulnerable population. The spatial representation of risk, visualising the extent of hazard or the distribution of vulnerability is therefore needed to successfully implement and address such strategies (Kienberger et al., 2009).

There are substantial areas of further research and effort required in this process. Firstly there needs to be work on the validation processes to test the outcomes of the maps. To some extent this has already occurred at a first order with a subsequent qualitative review by group government repre- sentatives both river basins. However a standardised sampling based approach to flood impact would be needed for full validation. Additionally, work needs to be carried out on the insertion of such approaches into the decision making processes and as well as getting a much deeper understanding of the potential to include spatial data as a proxy and/or augmentation for current commonly utilised georeferenced data sets such as the census. That said, the authors conclude that this is a practical and applicable process which provides a language of vulnerability that is relevant to the challenges of climate and socio-environmental change.

Additionally there is a substantive body of work to be undertaken to effectively include the diverse and substantial impact of governance on vulnerability and its spatial distribution. Currently the proxies for the mapping of effective governance are highly limited and as such methodologies to address this critical area are needed.

Acknowledgements. The Authors wish to thank the stakeholders of the various catchments who have contributed to this work as well as the field support of the Asian and European partners in organising the various stakeholder events which made this work possible. In addition the authors wish to acknowledge the contributions of FSU and ICIMOD more broadly in developing the foundations for this work.

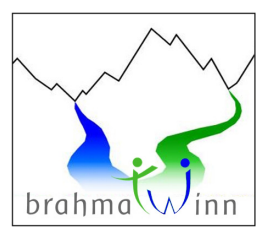

The interdisciplinary BRAHMATWINN EC-project carried out between 2006-2009 by European and Asian research teams in the UDRB and in the UBRB enhanced capacities and supported the implementation of sustainable Integrated Land and Water Resources Management (ILWRM).

\section{References}

Baatz, M. and Schäpe, A.: Multiresolution Segmentation: an optimization approach for high quality multi-scale image segmentation, in: Proceedings of the Angewandte Geographische Informationsverarbeitung XII, edited by: Strobl, J., Blaschke, T., Griesebner, G., et al., Beiträge zum AGIT Symposium Salzburg, 12-23, 2000.

Brooks, N., Adger, W. N., and Mick Kelly, P.: The determinants of vulnerability and adaptive capacity at the national level and the implications for adaptation, Global Environ. Chang., 15, 151163, 2005.

Carver, S. J.: Integrating multi-criteria evaluation with geographical information systems, Int. J. Geogr. Inf. Syst., 5, 3, 321-339, 1991.

Chakraborty, J., Tobin, G., and Montz, B.: New process to assessing vulnerability and variability in geophysical risk and social vulnerability to natural hazards, Natural Hazards Review, 6(1), 23-33, 2005.

Cutter, S., Mitchell, J., and Scott, M.: Revealing the vulnerability of people and place: a case study of Georgetown County, South Carolina, Ann. Assoc. Am. Geogr., 90(4), 713-737, 2000. 
Giupponi, C., Sgobbi, A., Mysiak, J., Camera, R., and Fassio, A.: NetSyMoD: an Integrated Approach for Water Resources Management, in: Integrated Water Management: Practical Experiences and Case studies, edited by: Meire, P. et al., Springer Netherlands, 69-93, 2008.

IPCC: Climate Change 2001: Impacts, Adaptation and Vulnerability, Contribution to the Working Group I to the third assessment report of the Intergovernmental Panel on Climate Change (IPCC), Cambridge University Press, Cambridge, 2001.

Jones, B. and Andrey, J.: Vulnerability index construction: methodological choices and their influence on identifying vulnerable neighborhoods, International Journal of Emergency Management, 4(2), 269-295, 2007.

Kienberger, S., Lang, S., and Zeil, P.: Spatial vulnerability units expert-based spatial modelling of socio-economic vulnerability in the Salzach catchment, Austria, Nat. Hazards Earth Syst. Sci., 9, 767-778, doi:10.5194/nhess-9-767-2009, 2009.

Lang, S., Zeil, P., Kienberger, S., and Tiede, D.: Geons - policyrelevant geo-objects for monitoring high-level indicators, in: Geospatial Crossroads @ GI_Forum '08, Proceedings of the Geoinformatics Forum Salzburg, edited by: Car, A., Griesebner, G., and Strobl, J., Heidelberg, Wichmann, 180-185, 2008.
Malczewski, J.: On the Use of Weighted Linear Combination Method in GIS: Common and Best Practice Approaches, Transactions in GIS, 4(1), 5-22, 2000.

Odeh, D. J.: Natural Hazards Vulnerability Assessment for Statewide Mitigation Planning in Rhode Island, Natural Hazards Review, 3(4), 177-187, 2002.

O'Neill, B. C., MacKellar, F. L., and Lutz, W.: Population and climate change, Cambridge University Press, Cambridge, 2001.

Sharma, N., Amoako Johnson, F., Hutton, C. W., and Clark, M.: Hazard, Vulnerability and Risk on the Brahmaputra Basin: A Case Study of River Bank Erosion, in: Analysis of Climate Change Impacts on Water Resources For Developing Economies: Successes and Challenges, edited by: Adeloye, A. J. and Ojha, C. S. P., Open Journal of Hydrology, 113-114, 2010.

Unwin, D. J.: GIS, spatial analysis and spatial statistics', Prog. Hum. Geog., 20(4), 540-441, 1996.

Villagrán, J. C. V.: Vulnerability: a conceptual and methodological review, UN University Institute for Environment and Human Security, 4/2006, 64 pp., 2006.

Wu, S. Y., Yarnal, B., and Fisher, A.: Vulnerability of Coastal Communities to Sea-Level Rise: a Case Study of Cape May County, New Jersey, USA, Clim. Res., 22, 255-270, 2002. 